\title{
Impact Study on Mass Evacuation in Urban Underground Passages
}

\author{
Yizhou Chen, Rui Yang, and Shifei Shen
}

\begin{abstract}
The primary goal of mass evacuation in urban underground passages or subways is to evacuate as many evacuees as possible to safe areas in the shortest time when emergency events occur. This paper chooses the underground passages of one subway station in Beijing as research object, and uses a study method which combines by sites investigation, field test and computer simulation of the buildingEXODUS software. We present a depth analysis of the related factors which include the number and width of passage, channelization setting and the number of pedestrians with the evacuation time. And the influential effect of public opinion is explained by using big data technology. In addition, pedestrians evacuation condition are recorded in three evacuation period, the morning peak, common and evening peak by the observation and statistic obtained with video, and build the model to simulate the change of evacuation time with pedestrians. So it reveals when the number of pedestrians gets reach to more than 200, evacuation time increases significantly and the field experiment and simulation condition are consistent basically ${ }^{1}$.
\end{abstract}

Index Terms-Underground passage, mass evacuation, impact, building EXODUS.

\section{INTRODUCTION}

At present, the mass evacuation of underground passages has become an indispensable link in urban emergency evacuation of China. However, the study of the aspect is not so much, of which the relevant theoretical basis is still relatively weak, even is very difficult [1], [2]. Therefore, the impact study on the large-scale crowd evacuation when there's an emergency event in urban underground passages, so as to improve the ability of the crowd evacuation, has become a key subject that can make a far-reaching implication on the urban safety and social stability [3], [4].

Underground passages and subway systems have been constructed in many big cities in China. Computer simulation technology developed overseas is commonly applied in working out safety management scheme [5], [6]. These simulations can be used to analyze the evacuation of buildings, subways, stadiums and traffic networks. And in the process of planning, simulation model provides the assessment network clearance time or detects bottleneck problems for emergency evacuation [7]. When researchers pass through the streets safely by underground passages,

Manuscript received October 15, 2014; revised December 29, 2014. This work was supported by the National Science Foundation for Post-doctoral Scientists of China under Grant 2014M560990.

Yi zhou Chen is with Tsinghua University, Institute of Public Safety Research, Beijing, 100084, China (e-mail: yzchen2013@ tsinghua.edu.cn).

Rui Yang and Shifei Shen is with the Department of Engineering Physics, Tsinghua University, Beijing, 100084, China (e-mail: ryang@mail.tsinghua.edu.cn, shensf@tsinghua.edu.cn). studies shows that pedestrians subjective conditions worse than objective conditions [8]. Jorge A. Capote, et al. present a real-time model integrated in a Decision Support System (DSS) for emergency management in road tunnel, the main difference is that the proposed model can provide results faster than real-time (less than $5 \mathrm{~s}$ ) while the run time of the other models is really higher [9]. A novel approach to represent space, which called the 'Hybrid Spatial Discretisation' (HSD), in which all three spatial representations can be utilized to represent the physical space of the geometry within a single integrated software [10]. A loudspeaker, which provided people with an alarm signal and a pre-recorded voice message, was found to perform particular well in terms of attracting people to the exit, independent of which side of the tunnel the participants were following [11]. To test the predictive capabilities of different evacuation modeling approaches to simulate tunnel fire evacuations, the study is based on the a priori modeling vs. a posteriori modeling of a set of tunnel evacuation experiments performed in a tunnel in Stockholm, Sweden [12]. Without crowding within the aisle, it would reduce the evacuation time by optimal design for the width of the entrance, opening exits and layout of escaping passages [13]-[15].

Therefore, how to calculate the ability of emergency evacuation accurately in underground passages or subway tunnels, and to analyze its bottleneck are the basis of improving the efficiency of emergency evacuation and preventing mass casualties in accidents. And they are also taking the important part in planning, designing and organizing passengers flows for underground passages or subway system.

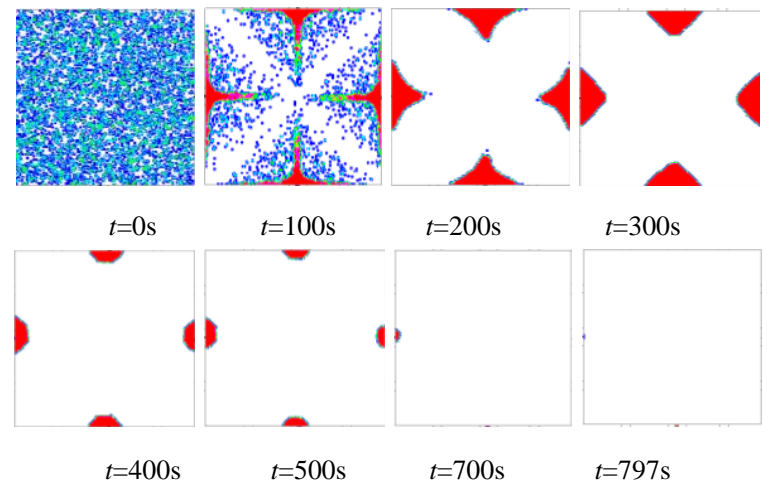

Fig. 1. Simulation scenario of four exits with building EXODUS.

\section{ANALYSIS OF IMPACT FACTORS}

It was clear from the results of mass evacuation cases of underground passages or subway station, evacuation time has great relationship with factors of the number of passage, 
width, canalization setting and the number of pedestrians. In addition, the influential effect of public opinion is also significant after emergency event.

\section{A. The Number of Passage Exit}

The number of exit is an important indicator which can influence evacuation of people. In this case, we assume a total of 10000 people are evacuated, in the area of 10000 square meter, we set the exit width to 3 meter and the number of the exit is respectively $4,6,8$ and 10 , and with a velocity of $1.2 \mathrm{~m} / \mathrm{s}$. The scenario of evacuation simulation with building EXODUS is shown in Fig. 1.

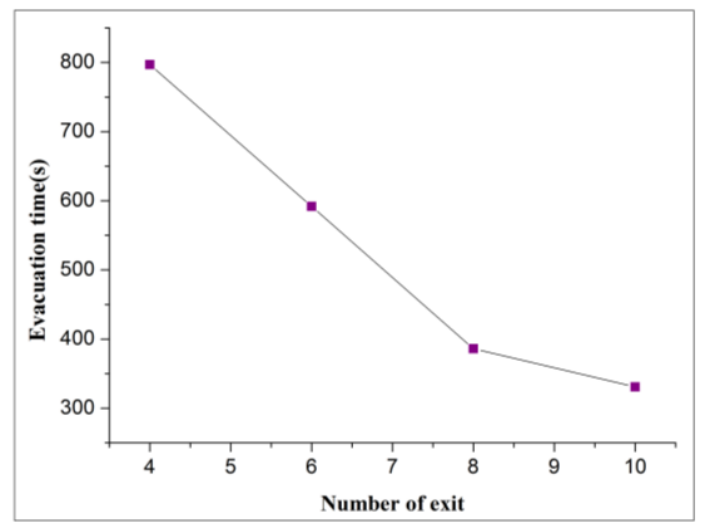

Fig. 2. Number of exit-evacuation time.

Fig. 2 shows the increase of the number of evacuating exits directly improves the efficiency of the evacuation. When there're 4 evacuating exits, evacuation time is $797 \mathrm{~s}$, however, when the number of evacuating exits increases to eight, evacuation time is $386 \mathrm{~s}$. This means that when the number of evacuating exit multiplies, evacuation efficiency doesn't increase in equal proportion. The decline of the number of pedestrian out of each exit, directly increases the degree of order of pedestrian evacuation. However, when the number of exits increases to a certain amount, the efficiency of evacuation cannot be improved anymore. Therefore, the number of exits of the building facilities should be set rationally according to the maximum capacity of venues.

\section{B. The Width of Passage Exit}

The effective width of the passage is an important factor which can influence evacuation ability of the pedestrian crossing [16], [17]. According to Code of Design on Building Fire Protection and Prevention (GB50016-2006) [18], the width of safety exit is obtained from the expression: $\mathrm{W}=$ $S \cdot D \cdot E$.

where $\mathrm{W}$ is calculative width of the safety exit $(\mathrm{m}), \mathrm{S}$ is the area of Business hall $\left(\mathrm{m}^{2}\right)$, D is the person density of Business hall $\left(\right.$ person $\left./ \mathrm{m}^{2}\right), E$ is the safety exit width index $(\mathrm{m} / 100$ person).

The model is established that there's a total of 10000 people are evacuated and four exits, which respectively are 3 , 6,8 and 10 meters in this case and with a velocity of $1.2 \mathrm{~m} / \mathrm{s}$.

Fig. 3 shows that the increase of the evacuation exit width directly improves the efficiency of the evacuation. When exits width is $3 \mathrm{~m}$, evacuation time is $797 \mathrm{~s}$, however, when the width increases to $4 \mathrm{~m}$, evacuation time is $329 \mathrm{~s}$. This means that when the width of evacuation exit multiplies, evacuation time doesn't decrease in equal proportion, but need more time. Therefore, the exit width of the building facilities should be set rationally according to the need of venues.

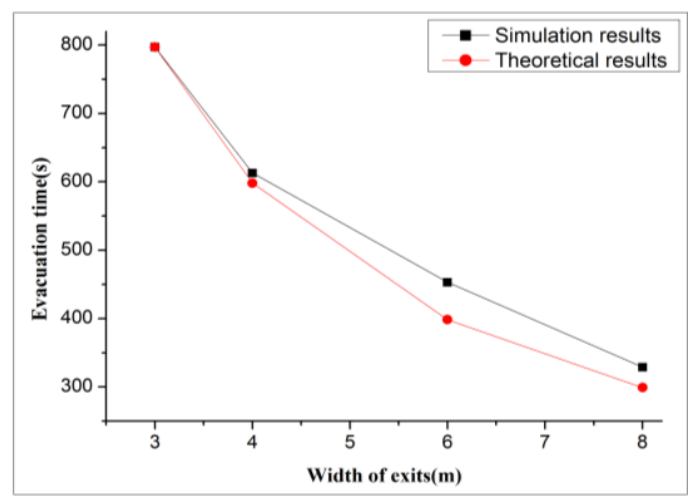

Fig. 3. Relation width of exits and evacuation time.

\section{Passage Canalization Setting}

Evacuation speed and the interference among pedestrians can be influenced by the width and the number of evacuating exits, in addition, the reasonable passage canalization set also can increase pedestrians evacuation efficiency. Stimulating a situation that the evacuation door width is $1 \mathrm{~m}$, and the number of evacuation is 100 people, and with a velocity of $1.2 \mathrm{~m} / \mathrm{s}$. We set up four kinds of circumstances, in which pedestrian evacuate respectively on their own, one passage canalization being set, two passage canalization being set, and three passage canalization being set.

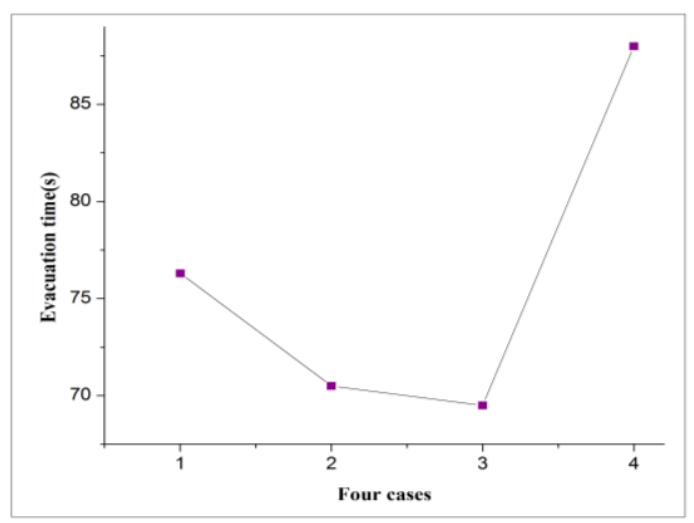

Fig. 4. The four kinds of passages canalization setting and evacuation time.

Fig. 4 shows that when the emergency evacuation happen, setting effective channelized diversion objects at the entrances and exits, can reduce the evacuation conflict among pedestrians and also can increase the speed and evacuation order, in order to improve the efficiency and safety. But when too many channelized objects are set up in evacuating exits, it will go too far and the evacuation efficiency will be reduced.

\section{The Number of Pedestrian}

The number of pedestrians is also an important factor. In this case, we assume 50,100, 150, 200, 250, 300 people separately are evacuated at $1.2 \mathrm{~m} / \mathrm{s}$, across the underground passage with length of 20 meter and the width of 2 meter. And the scenario of evacuation simulation is shown in fig. 5 and relation graph of pedestrians and evacuation time is 
shown in Fig. 6.

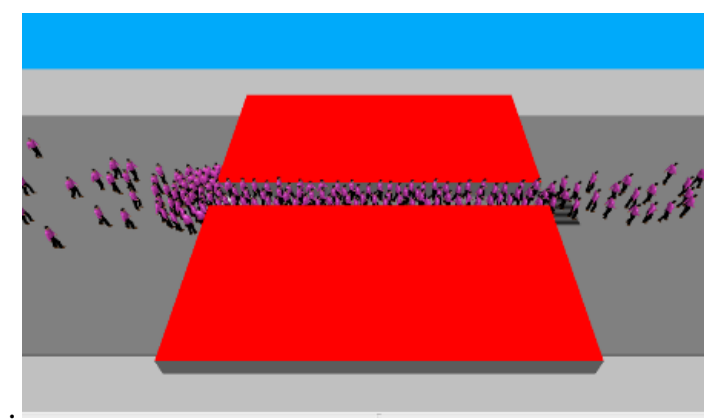

Fig. 5. The scenario of evacuation simulation.

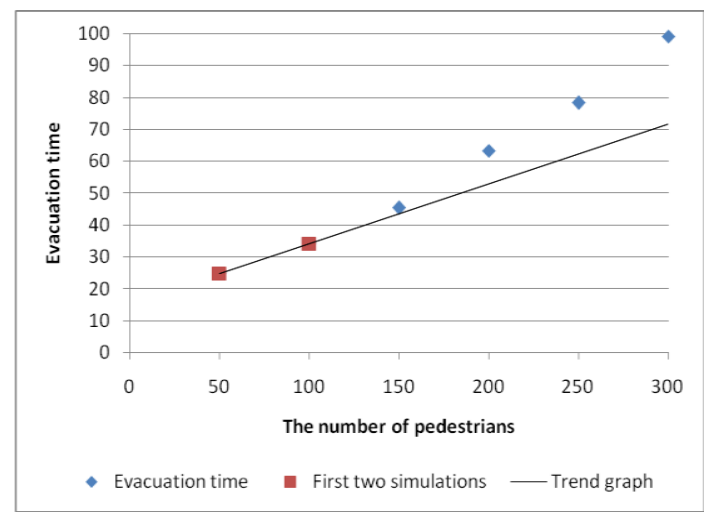

Fig. 6. The relation of number of pedestrians and evacuation time.

In the Fig. 6, red dots indicate the first two simulation results when the number of pedestrians assumed at 50 and 100 , and all dots mean that the evacuation time in the sixth simulation. It shows that the evacuation time is rising with the number of pedestrians increasing. However, the trend line graph is developed according to the average value of first two simulations with 50 and 100 pedestrians. Actually, the evacuation time is not increasing in proportion to the number of pedestrians. When the more demand increased, and the higher congestion in the passage, it's results in a decline in evacuation efficiency, especially when evacuees gets reach to more than 200, evacuation time increases significantly as same as we observed. Besides, the impaired disabled are also led to a decline of the evacuation efficiency [19]. So the related departments should strengthen control of the number of pedestrians in passages in order to reduce the accident interference in the process of evacuation.

\section{E. Effect of Public Opinion}

Emergency monitoring in underground passage or subway refer to that of the related network public opinion, especially when group emergency incidents occur. It's difficult for the department of administration to make judgments and decisions of the information because of so many changing factors of emergencies, complex internal relationship, unpredictable developing trend and complicated relevant information. Incidents of this kind have intense abruptness, strong social influence and short think time for policy makers, and the consequences will be serious if you can't get the accurate information and make judgments in good time. However, collection, sorting and discrimination of all the information can't be handled leisurely for policy makers under great pressure, some valuable information may be omitted or ignored, so that the decision-making of treatment is misleading.

New opportunities and prospects for emergency management in urban area have been brought in big data era. The bigger the scale of data about city underground passage or subway station, the more difficult to handle, but the better value may be got from the data mining. In crisis situations, department of emergency management can understand the needs, demands and feelings of public by collecting and analyzing public opinion using big data technology, they can also monitor hot issues and track the source of all information with text messages, microblog, wechat and search engine. Therefore, it's an important influence factor in evacuation of underground passage or subway station in urban area for public opinion.

\section{SERVICE LEVEL}

Compared with Westerners, the characteristics of pedestrian traffic and the factors of physiological and psychological in China have a greater difference. Therefore, with the research results from abroad and the pedestrian's characteristics and investigation, classification indexes of service level for pedestrians proceeding are brought forward. As shown in Table I.

TABLE I: THE RECOMMENDS TABLE OF THE STANDARD FOR PEDESTRIANS SERVICE LEVEL IN CHINA

\begin{tabular}{ccccc}
\hline \hline $\begin{array}{c}\text { Service } \\
\text { Level }\end{array}$ & $\begin{array}{c}\text { Density } \\
(\text { person/m }\end{array}$ & $\begin{array}{c}\text { Per Capita } \\
\text { Spaces } \\
\left(\mathrm{m}^{2} / \text { person }\right)\end{array}$ & $\begin{array}{c}\text { Pedestrian } \\
\text { Flow } \\
(\text { Person/ } \\
(\min \cdot \mathrm{m}))\end{array}$ & $\begin{array}{c}\text { Velocity } \\
(\mathrm{m} / \mathrm{s})\end{array}$ \\
\hline $\mathrm{A}$ & $<0.2$ & $>5$ & 25 & $1.1 \sim 1.5$ \\
$\mathrm{~B}$ & $0.2 \sim 0.28$ & $3.5 \sim 5$ & 32 & $0.9 \sim 1.1$ \\
$\mathrm{C}$ & $0.28 \sim 0.5$ & $2 \sim 3.5$ & 45 & $0.8 \sim 0.9$ \\
$\mathrm{D}$ & $0.5 \sim 0.83$ & $1.2 \sim 2$ & 62 & $0.7 \sim 0.8$ \\
$\mathrm{E}$ & $0.83 \sim 2.5$ & $0.4 \sim 1.2$ & 90 & $0.5 \sim 0.7$ \\
$\mathrm{~F}$ & $>2.5$ & $<0.4$ & Wave & $<0.5$ \\
\hline \hline
\end{tabular}

Under general condition, pedestrian density of the crowded underground passages should be controlled according to the corresponding value of $\mathrm{C}$ level of service. While pedestrian density of the peak can reach to D level of service in a short time, admissible to E level at moment.

\section{Evacuation Model}

\section{A. Field test}

One underground passage of subway station in Beijing as study object in the paper, has the unidirectional width of 2 meters (see Fig. 7).

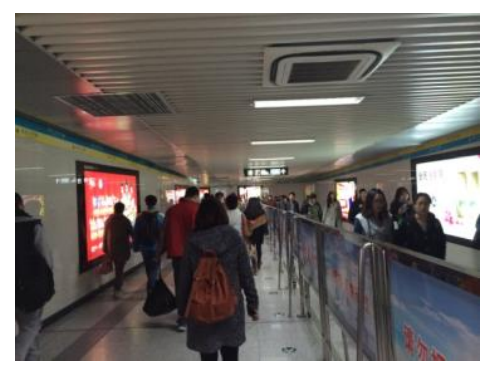

Fig. 7. The underground passage of subway station in Beijing. 
In the field test, the number of evacuees each one minute of an interval are recorded in three evacuation period, the morning peak, common and evening peak by the observation and statistic obtained with video, as shown in Table II.

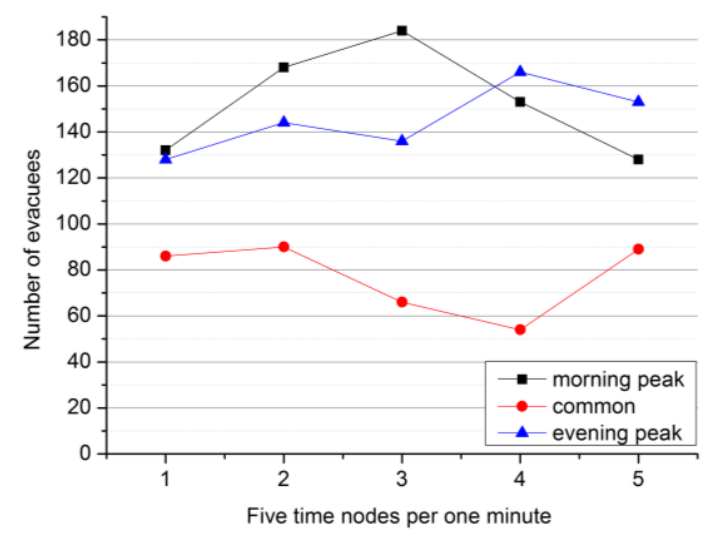

Fig. 8. The underground passage of subway station in Beijing.

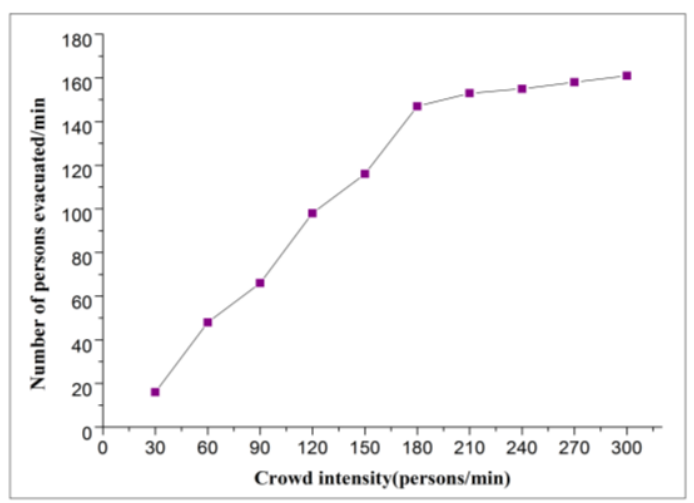

Fig. 9. The relation of crowd intensity and the number of pedestrians per minute.

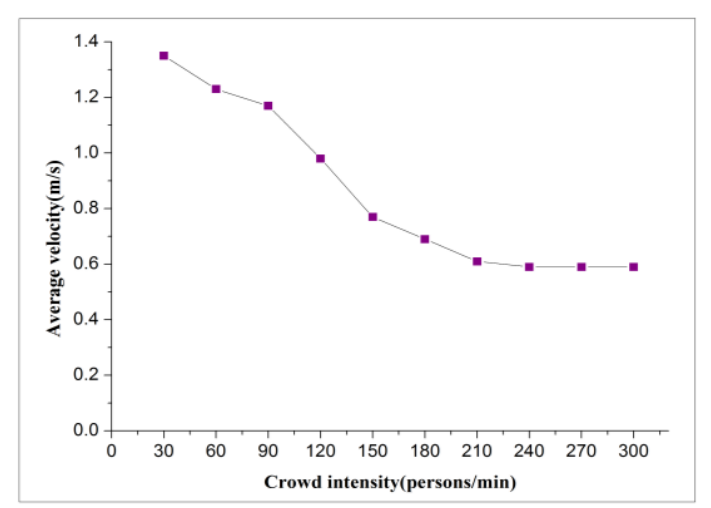

Fig. 10. The relation of crowd intensity and average walking velocity.

From the Fig. 8, it is clear that the number of pedestrians is within 90 in the common period (note: the width is 2 meter), so pedestrian density range of the underground passage can be controlled, service level between $\mathrm{B}$ and $\mathrm{C}$ by obtained from the Table I. However, in the evacuation period in morning peak and evening peak, the number of pedestrians of the underground passage is more than 120 , and it is relatively crowed, the service level has reached the E, and even up to F in some time.

From above, the E level of service is admissible at moment. However, the underground passage is overcrowding with a long time, so the department of metro or transport should be caused take seriously, to take measures so that the traffic jams stampede.

From above, the E level of service is admissible at moment. However, the underground passage is overcrowded in a long time, so the department of metro or transport should take seriously attention, to take measures to prevent the traffic jams and even stampede accidents or other emergency events caused by it.

\section{B. Simulation}

The model is built according to the same parameters with the underground passage, and with a velocity of $1.2 \mathrm{~m} / \mathrm{s}$, to conduct the walking velocity and the evacuation simulations as shown in Fig. 9 and Fig. 10 by setting 10 groups with different intensity of pedestrian flow from 30 to 300 pedestrians are passing the underground passage in one minute.

Fig. 9 and Fig. 10 show that a decline in the walking velocity of the pedestrian evacuation is brought about, along with the increase of the demand of pedestrian evacuation and the degree of crowding of the passage. The number of pedestrian evacuation increases with the enlarging of demand, however, passage evacuation capacity reaches the limit to a certain intensity, the number of evacuation does not continue to increase accordingly. And the simulation results are consistent basically with field test.

Therefore, pedestrian passages should be evaluated when evacuation passageways are set up in combination with evacuation flow intensity, at the meantime, we suggested considering not only the limit of the passage evacuation capacity ,but also the suitable evacuation walking speed and the time crossing the evacuation passageway, in order to reduce interference of the emergency in the process of evacuation.

TABLE II: THE NumBer OF EVACUEES IN THE THREE PERIOD, MORNING

\begin{tabular}{cccccc}
\multicolumn{7}{c}{ PEAK, COMMON AND EVENING PEAK } \\
\hline \hline $\begin{array}{c}\text { Evacuation } \\
\text { period }\end{array}$ & $\begin{array}{c}\text { People } \\
\text { First } \\
1 \text { minute }\end{array}$ & $\begin{array}{c}\text { People } \\
\text { Second } \\
\text { 1minute }\end{array}$ & $\begin{array}{c}\text { People } \\
\text { Third } \\
\text { 1 minute }\end{array}$ & $\begin{array}{c}\text { People } \\
\text { Forth 1 } \\
\text { minute }\end{array}$ & $\begin{array}{c}\text { People } \\
\text { Five 1 } \\
\text { minute }\end{array}$ \\
\hline $\begin{array}{c}\text { morning } \\
\text { peak } \\
\text { common } \\
\text { evening } \\
\text { peak }\end{array}$ & 132 & 168 & 184 & 153 & 128 \\
\hline \hline
\end{tabular}

\section{CONCLUSION}

In this paper we have presented a comprehensive study approach and considered many factors to make a plan for pedestrian evacuation in urban underground passages or subways.

1) The number and width of passages for pedestrians are so two important parameters related to affect the evacuation capability. So building facilities should be set rationally according to the maximum capacity of venues.

2) The demand for quantity of evacuees has a prodigious impact on the evacuation efficiency. So effective analysis of the relationship between quantity of evacuees and evacuation speed is conducive to provide a reference basis for emergency evacuation in a place 
which has high-density public, and also take examples for the safeguard mechanisms in big public buildings.

3) The influence factors of pedestrian speed are so many, which also have the large range. According to the results of domestic and international research relevant, it shows that due to the differences of pedestrian age, physiology (height, weight, etc.) and investigating locations, the pedestrian speed is usually from $1.0 \mathrm{~m} / \mathrm{s}$ to $1.4 \mathrm{~m} / \mathrm{s}$.

4) It is extremely important for improved mechanism of public opinion monitoring, timely and effective collection and analysis of public opinion information, and a comprehensive grasp of various kinds of information closely related to the event in emergency events.

\section{ACKNOWLEDGEMENT}

The authors appreciate the Project supported by National Science Foundation for Post-doctoral Scientists of China (NO. 2014M560990).

\section{REFERENCES}

[1] C. S. Jiang, Y. F. Deng, C. Hu, H. Ding, and W. K. Chow, "Crowding in platform staircases of a subway station in China during rush hours," Safety Science, vol. 47, pp. 931-938, 2009.

[2] S. Chen, B. Mulgrew, and P. M. Grant, "A clustering technique for digital communications channel equalization using radial basis function networks," IEEE Trans. on Neural Networks, vol. 4, pp. 570-578, July 1993.

[3] C. S. Jiang and Y. Ling, "Numerical simulation of emergency evacuation of a subway station," Architectural Science Review, vol. 52, pp. 183-193, 2009.

[4] Y.Z. Chen, S. J. Cai, and Y. F. Deng, "Simulation study on main Affect factors to the evacuation corridor," Applied Mechanics and Materials, pp. 170-173, 2012.

[5] C. S. Jiang, F. Yuan, and W. K. Chow, "Effect of varying two key parameters in simulating evacuation for subway stations in China," Safety Science, vol. 48, pp. 445-451, 2010.

[6] M. H. Zhong, C. L. Shi, and X. W. Tu, "Study of the human evacuation simulation of metro fire safety analysis in China," Journal of Loss Prevention in the Process Industries, vol. 21, pp. 287-299, 2008.

[7] C. L. Shi, M. H. Zhong et al., "Modeling and safety strategy of passenger evacuation in a metro station in China," Safety Science, vol. 50, pp. 1319-1332, 2012.
M. Mahdavinejada, A. Hosseinib, M. Alavibelmana, "Enhancement HSE factors in pedestrian underpass regarding to chemical hazards," Social and Behavioral Sciences, vol. 51, pp. 10-14, 2012.

[8] J. A. Capote, D. Alvear, O. Abreu, A. Cuesta, and V. Alonso, "A real-time stochastic evacuation model for road tunnels," Safety Science, vol. 52, pp. 73-80, 2012.

[9] N. Chooramun, P. J. Lawrence, and E. R. Galea, "An agent based evacuation model uilising hybrid space discretisation," Safety Science, vol. 50, pp. 1685-1694, 2012.

[10] K. Fridolf, E. Ronchi, D. Nilsson, and H. Frantzich, "Movement speed and exit choice in smoke-filled rail tunnels," Fire Safety Journal, vol. 59, pp. 8-21, 2013

[11] E. Ronchi, "Testing the predictive capabilities of evacuation models for tunnel fire safety analysis," Safety Science, vol. 59, pp. 141-153, 2013.

[12] J. Jingwei, W. Zhen, W. Ke et al., "An investigation of effects on evacuation capacity of fire-protection evacuation walk caused by internal and external door width," Journal of Shenyang Jianzhu University (Natural Science), vol. 29, pp. 698-702, 2013.

[13] G. Y. Jeon, J. Y. Kim, W. H. Hong, and G. Augenbroe, "Evacuation performance of individuals in different visibility conditions," Building and Environment, vol. 46, pp. 1094-1103, 2011.

[14] Y. Z. Chen, R. Yang, and Y. Liu, "Strategy study on mass evacuation with LBS information," Web-Age Information Management, pp. 141-150, 2014.

[15] W. Bles, S. Nooy, and L. C. Boer, "Influence of ship listing and ship motion on walking speed," in Proc. the First Conference on Pedestrian and Evacuation Dynamics, Duisburg, Germany, 2011, pp. 437-452.

[16] J. M. Watts, "Computer models for evacuation analysis," Fire Safety Journal, vol. 12, pp. 237-245, 1987.

[17] Code of Design on Building Fire Protection and Prevention, 2006.

[18] C. S. Jiang, S. Z. Zheng et al., "Experimental assessment on the moving capabilities of mobility-impaired disabled," Safety Science, vol. 50, pp. 974-985, 2012.

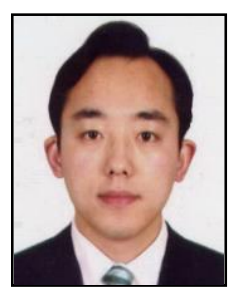

Yizhou Chen is a postdoctoral researcher in Institute of Public Safety Research for safety science and emergency management, Department of Engineering Physics, Tsinghua University. He received the Ph.D. degree in safety science and engineering from the University of Science and Technology Beijing, China, in 2013. He has studied on modeling and simulation of transportation evacuation in the Department of Civil Engineering and Engineering Mechanics, University of Arizona, USA, as a visiting scholar at between 2010 and 2011. His research interests include simulation and emergency decision-making, risk assessment and safety planning, emergency evacuation and refuge, emergency resource allocation and distribution, personnel safety and protection, emergency standards making, etc. He has published more than 20 technical papers. And his current research emphasis is on modeling and simulation of crowd evacuation for high density area. 